\title{
PNEUMONIA IN MEASLES
}

BY

J. B. ELLISON, M.A., M.D., D.P.H.*

(From the Grove Fever Hospital, London.)

The steady decline in the virulence of diphtheria and scarlet fever which has been in progress during the present century has thrown into sharper prominence the continued severity and fatality of measles.

Taking epidemic and non-epidemic years together, measles is responsible for 0.8 per cent. of deaths from all causes in this country, and must be held responsible for much chronic ill-health, as a result of its pulmonary complications. In average epidemics all but a negligible proportion of the deaths occur within the first five years of life in communities in which measles is endemic.

Cause of death in measles.-On the average about four-fifths of measles deaths are directly attributable to pneumonia in one form or another, bronchopneumonia of a severe type being responsible, as is well known, for the greatest number.

During the 1927-28 epidemic, 86 per cent. of deaths occurring from measles in Metropolitan fever hospitals were due to pneumonia. From 19161927 inclusive, measles appears as a cause of death in the Grove Hospital register in 193 cases. The immediate cause of death is given as bronchopneumonia in 153 cases ( 80 per cent.), lobar pneumonia 6 cases ( 3 per cent.), and other miscellaneous causes in 34 cases (17 per cent.). On the whole, when large numbers are considered, the case mortality in England has not fluctuated very much over a number of years, though the segregation of severe cases in various institutions has at times been productive of tables of statistics which are by no means representative of normal conditions.

Treatment of measles in hospitals.-The case mortality among cases treated in hospitals appears to be so gravely in excess of that observed in those which are left at home, that the argument is sometimes advanced that no attempt should be made to accumulate cases of measles in large institutions, on account of the dangerous infectivity of measles pneumonia under the overcrowded conditions which are likely to exist in hospital wards during epidemics (Sowden ${ }^{26}$ ). The L.C.C. fever hospital statistics (1927-28) do not, however, support this contention. The case mortality among those children who were admitted to hospital suffering from pneumonia was 31.7 per cent., while among those who were free from pneumonia on admission it was only 1.9 per cent. There is no consensus of opinion as to whether or no pneumonia in measles should be regarded as dangerously infective, but in this country it is not usually so regarded, and no attempt is made as a rule to segregate cases with

\footnotetext{
* Part of a thesis accepted for M.D. degree (Cantab.).
} 
pneumonia from the rest. On the other hand the late C. B. Ker wrote in his well-known text-book of infectious diseases, 'I have no doubt the condition may be infectious from patient to patient,' but he supplied no information on the frequency of such infection. French writers appear to be unanimously of the opinion that measles pneumonia is highly infectious, and Hallé ${ }^{9}$ has stated that every case of measles should be strictly isolated.

During the 1927-28 epidemic an opportunity occurred at the Grove Hospital of studying the effect of nursing measles cases in isolation. The cubicles which were used consisted of glass partitions, seven feet in height, within the main body of the ward, access being afforded by a central corridor. Isolation was, therefore, not absolute, since the patients breathed a common atmosphere, although a spray infection could be practically excluded. The results were :-

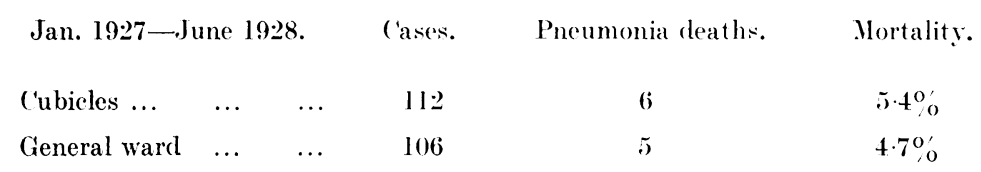

During the period under review the average hospital death rate from pneumonia was $\check{\mathfrak{5}} \cdot \mathbf{4}$ per cent., the same as that of the cubicle ward. It may, I think, be concluded that measles can be safely nursed in general wards provided that the density of beds is kept within proper limits. A minimum of 144 square feet of floor space per bed should be maintained.

\section{Previous investigations on pathology and bacteriology.}

About fifty years ago Cornil and Babes, writing in the Traité de Medicine of Charcot, Bouchard, and Brissot, described a form of broncho-pneumonia which they considered might be due to the unknown virus of measles, since it did not appear to be associated with any of the micro-organisms invading the respiratory tract familiar to them. These observations were made before the discovery by Pfeiffer of the so-called hæmophilic group of bacteria. According to Cornil and Babes the essential lesion consisted of an acute inflammation of the peri-bronchial lymphatics leading to a diffuse infiltration of the inter-alveolar connective tissue. The mortality was very high, and the authors observed that in those cases which survived, the disease tended to run a prolonged course closely resembling pulmonary tuberculosis from which, in fact, it was but rarely distinguished.

Interstitial pneumonia.-The occurrence of acute interstitial pneumonia has been frequently remarked in measles.

In 1884 Delafield ${ }^{4}$ emphasized this and pointed out that consolidation of the lung was generallydue to lateral pressure on the alveoli adjacent to the bronchioles, being in fact a species of atelectasis.

Steinhaus ${ }^{27}$, dealing with measles in children, distinguished this species from the common lobular type of broncho-pneumonia in which there is a catarrhal exudate, and noticed that the alveoli may be filled with fibrin. Hecht ${ }^{10}$ gave a very similar account. 
In $1921 \mathrm{MacCallum}^{19}$ in an exhaustive monograph described the types of pneumonia occurring in a large outbreak of measles among soldiers in camp. He considered that focal areas of consolidation in the lung resulted from a primary bronchiolitis and peri-bronchiolitis produced by the propagation of an inflammatory irritant by way of the lymphatics. He distinguished two varieties of inflammatory process : one, an acute focus with exudate into the alveoli, fibrin being always abundantly present in recent cases; secondly, a more chronic focus proceeding in the form of a proliferative interstitial peri-bronchitis with striking changes in the interstitial tissue but no exudate into the alveoli. This second type was prone to lead to suppuration in the lung and empyema. The organism most frequently discovered was a hæmolytic streptococcus. It must be noted that all MacCallum's patients were young adults, and that the whole epidemic spread from a single limited geographical centre, since it is principally on the strength of this epidemic that hæmolytic streptococci have been so generally considered to be the organisms most prevalent in the lungs in measles. Previously Hektoen had found hæmolytic streptococci predominating in measles in military camps, but Knowlton was doubtful of the significance of these findings. Knowlton made cultures from the throats of 458 cases of measles (mortality $2 \cdot 7$ per cent.), and found hæmolytic streptococci present in 122 cases. Pncumonia occurred in 10.6 per cent. of these cases. In 336 cases which were negative to hæmolytic streptococci, pneumonia occurred in $\mathbf{1 0 . 4}$ per cent. It was, however, noted that streptococci predominated in the pneumonias occurring in those patients who were previously negative to streptococci. Knowlton considered that these findings pointed to the conclusion that in many cases the primary organisms associated with measles pneumonia, tend to be replaced by hæmolytic streptococci at a later stage.

Frequency of empyema.-Empyema was a frequent occurrence in all these camp epidemics and I am inclined to believe that the frequency of empyema in measles may be regarded as in some measure an index of the prevalence of hæmolytic streptococci.

TABLE 1.

CompaRative FRequency OF EMPYEMA IN PNEUMONIA.

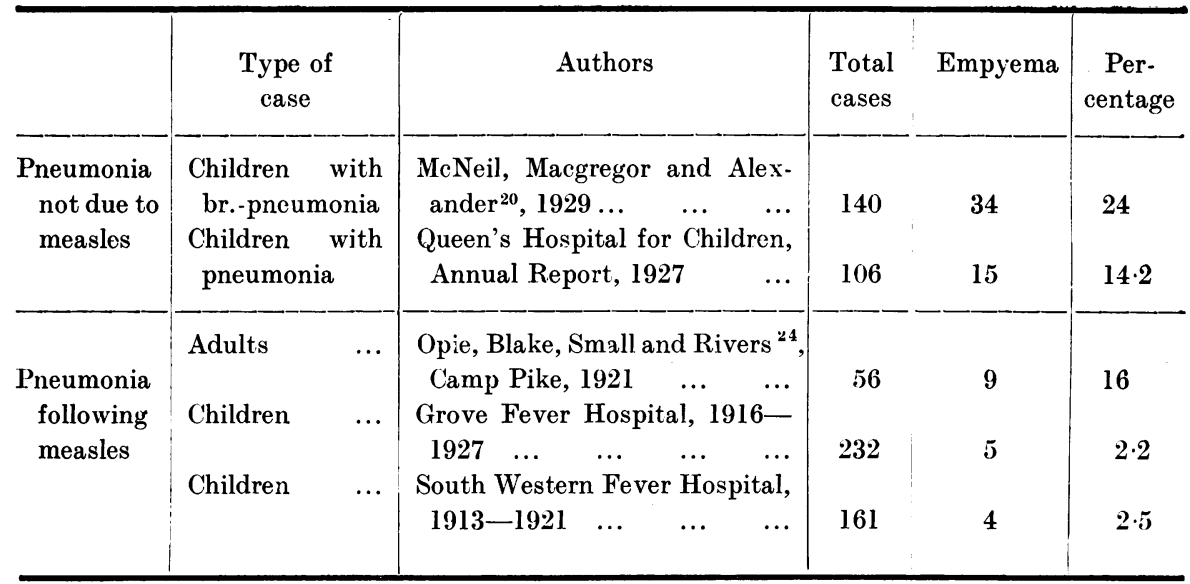

It can be seen from Table 1 that there is a significant difference between the incidence of empyema in childhood when measles is the predisposing condition when compared with other forms of broncho-pneumonia. Now measles is accompanied by such severe forms of pneumonia that the relative immunity of London children to empyema is not very easy to explain. The argument that in measles there is no tendency to the formation of purulent 
exudates is not supported by the observed frequency" of such exudates among adults ; moreover, in all such exudates hæmolytic streptococci are found with greater frequency than any other group of organisms, pneumococci being more frequent in primary forms of broncho-pneumonia. Pneumococcal pneumonia in measles appears to result from exaltation in virulence of the normally harmless saprophytes of the nasopharynx, and these are less liable to produce purulent effusions than are type I and II pneumococci.

Further, there is some reason to suppose that very young children (i.e., those in the age groups on which falls the maximum incidence of measles pneumonia) are relatively resistant to the invasions of streptococci. The different average age incidences of measles and scarlet fever may perhaps be quoted in support of this view, as well as the fact that the majority of infants in their first year of life are Dick-negative (Zingher ${ }^{33}$ ). The occurrence of effusions in the recent epidemic (1929-1930) is interesting in this connection. From October to February severe pneumonia was prevalent but no empyemata occurred. It was also observed that during the months of December, 1929, and January and February, 1930, hæmolytic streptococci were extremely scarce from any source (e.g., cultures from the mastoid, antrum, throats, etc.). Towards the end of February the streptococci began to appear again (the last 3 or 4 cases dealt with in this investigation were streptococcal pneumonias, and date from the second half of February): while in March four empyemata occurred, two of which were fatal, and in three of these cases the hæmolytic streptococcus was found in pure culture. In March, 1929, streptococical empyemata were also more frequently noted than in any other month on that occasion in connection with influenza.

On the whole, I think, there are good grounds for believing that scarcity of empyema in most epidemics of measles in children, is due to the comparative rarity of streptococcal pneumonia in young children suffering from this disease.

B. influenzæ in measles.-This association has been described by various authors.

MacCallum ${ }^{19}$ noted the association of organisms resembling the bacillus influenzæ (Pfeiffer) with streptococci in some of his cases and remarked :- ' It may be that they (B. influenzæ) tend to be associated with interstitial and organizing processes, and one might leap to the conclusion that they are responsible for these processes, or even that they are the forerunners of the streptococcus and pneumococcus infection.' Alteration in the bacterial flora of the lungs as the disease progresses has been noted by various authors. In another outbreak of measles in an army camp, Opie, Blake, Small and Rivers ${ }^{24}$ showed that pneumonia was due at the outset either to the pneumococcus alone, or to this organism associated with influenza bacillus, though certain of their cases became complicated later by a hæmolytic streptococcus. They also noted that empyema was rare in the absence of such a late infection. They considered that a common sequence of events in measles might be the same as that so frequently noted in influenza; first bronchial infection with B. influenzæ, then pneumonia due to the pneumococcus, followed at a later stage by necrosis and suppuration produced by hæmolytic streptococci. Such a sequence was observed in one of my series (Case 46).

Four hundred and eighteen cases among soldiers in camp on Salisbury Plain were examined by Eyre and Lowe ${ }^{5}$ who discovered streptococci in 96 per cent. and B. influenzæ in $72 \cdot 5$ per cent. of sputa, and in 2 cases B. influenzæ in pure culture in the lungs. The frequent appearance of B. influenzæ in the respiratory tract of patients with uncomplicated measles has been noted by Bordet $^{2}$, and especially in children by Davis ${ }^{3}$. 
Relation of measles to influenza.-Wolbach ${ }^{32}$ described acute interstitial pneumonia as a feature of the great influenza pandemic of 1918, and obtained the B. influenzæ in pure culture from the lungs in a number of cases. In many respects measles bears a close resemblance to influenza, especially as regards the pathology and bacteriology of the complications : thus to quote Hallé ${ }^{9}$ :-

- La flore bactérienne de ces complications (i.e.. measles pneumonia) est en effet le méme que celle des broncho-pneumonies grippales, en première ligne le streptocoque hemolytique, pur. ou associć au pneumocoque, au staphylocoque, ou au pneumobacille de Friedlander. IIs sont souvent précédes a un premier stade par un coceo-bacille quion est hien d'homologuer avec le bxcille de P'feiffer.'

Lewis ${ }^{15}$ discussing the occurrence of $\mathrm{B}$. influenzæ in measles considered that the periods during which the wide diffusion of the influenza bacillus has been found, have always been periods following the mild missed prevalences of true influenza of respiratory type. A comparison, however, of the crude death rates from both diseases over a number of years does not point to any intimate connection between them (see Table 2), but the true significance of

TABIS: 2.

DEATHS FROM MEASLES AND INFLCEXA, 1913-19233.

(ENGLaNd AND Wales.)

\begin{tabular}{|c|c|c|c|c|c|c|c|c|c|c|c|}
\hline & 1913 & 1914 & 1915 & 1916 & 1917 & 1918 & 1919 & 1920 & 1921 & 1922 & 1923 \\
\hline $\begin{array}{l}\text { Total deaths from } \\
\text { measles } \\
\text { Total deaths from } \\
\text { influenza }\end{array}$ & $\begin{array}{r}10,644 \\
6,394\end{array}$ & $\begin{array}{l}9,144 \\
5,964\end{array}$ & $\begin{array}{l}16,445 \\
10,484\end{array}$ & $\begin{array}{l}5,513 \\
8,791\end{array}$ & 10,538 & $\begin{array}{r}9,787 \\
112,329\end{array}$ & $\begin{array}{r}3.5334 \\
44,801\end{array}$ & $\begin{array}{r}7,190 \\
10,665\end{array}$ & $\begin{array}{l}2,241 \\
8.99 .5\end{array}$ & $\begin{array}{r}5,894 \\
21.498\end{array}$ & $\begin{array}{l}5,316 \\
8,461\end{array}$ \\
\hline
\end{tabular}

The II.A.B. measles case mortality of 1918 was $13 \cdot 2$, the highest recorded, but there does not appear to be any very clear correlation between the crude death rates. The high mortality of 1915 for measles is accounted for by outbreaks among troops in camp.

the B. influenzæ in influenza has hardly yet been decided, although after a temporary eclipse, it has undergone a certain rehabilitation"9 The matter is further complicated by the demonstration by many bacteriologists that the $B$ influenzæ is very widely diffused among perfectly healthy people, and this fact appears to have led to the undeserved neglect until quite recently of Pfeiffer's bacillus as a dangerous pathogenic agent.

Primary acute interstitial pneumonia in children.- In a recent important series of papers McNeil, MacGregor, and Alexander ${ }^{20}$ have noted the occurrence of acute interstitial pneumonia as a primary disease of children. They point out that the essential process is a progressive lymphangitis which begins in the peri-bronchial lymphatics, spreads down to the peri-vascular connective tissue of the lung and causes interstitial proliferation. They also observe that this mode of invasion is the reason for the severity of the disease, and for its undesirable consequences. 
The general picture presented in such cases appears to be identical with that which is found in many of the most acute cases caused through measles, some of which will be described later. The acute lymphangitis in measles cases can be observed post mortem. The submucous lymphatics of the larynx and trachea are invaded in the first place, and a rapid downward spread occurs into the peri-bronchial lymphatics. There are no definite lymphatic vessels demonstrable in the parenchyma of the lungs, but a remarkable endothelial proliferation of the alveolar wall is seen to occur. Some of the alveoli are compressed by this process, while those in any portion less affected by the morbid process become notably emphysematous. Sometimes there is an effusion of fibrin into neighbouring alveoli, but polymorphonuclears are always conspicuously rare (Fig. 1-4).

Working in connection with the authors quoted above, Glen Liston made a bacteriological examination in 40 cases showing this condition, and demonstrated the presence of B. influenzæ in 33 (85 per cent.) of them using Sopakar's medium. Reviewing the evidence he concludes that $B$. influenzæ may be considered as the true cause of this acute form of pneumonia, to which conclusion I can bring further support. It is interesting to note that Glen Liston found the organism six times in the blood stream, once in pure culture, and five times in association with other organisms.

The general conclusion reached was that the B. influenzæ opens a path for the invasion of the respiratory tract by secondary organisms which are the cause of empyema, abscess of the lung, bronchiectasis, etc. Only one of the cases dealt with in the papers here quoted was definitely attributable to measles.

Other organisms found in the lungs in measles pneumonia.-Various secondary invaders have been described in the lungs in measles besides the hæmolytic streptococcus, but streptococcus viridans of whatever species is rarely found. The hypothesis that measles may be caused by a greenproducing streptococcus, put forward by Tunnicliffe ${ }^{30}$, Ferry and Fisher ${ }^{6}$ and others, led Mair ${ }^{21}$ to examine the flora of the upper respiratory tract in fifty children in the early stages of measles by allowing them to cough over rabbitsblood agar plates. In no case did any colonies of streptococcus viridans develop although this type can be cultivated with ease from the tonsils at all stages of the disease. In my series (74 cases) they developed in three cases of pneumonia in pure culture from the lungs, and from the larynx in addition in one case (No. 71) which was complicated by acute laryngitis.

As would be expected the pneumococcus has frequently been found in measles pneumonia. Members of the heterogeneous fourth group are probably present in the great majority of cases

I have not had an opportunity of determining this point in the present investigation but the findings of Glynn and Digby ${ }^{7}$ appear conclusive These authors examined 879 cases of pneumococcal broncho-pneumonia with this result :-

$\begin{array}{rrrrr}\text { Type I } & \ldots & \ldots & 17 & (1.9 \%) \\ \text { Type II } & \ldots & \ldots & 79 & (9.0 \%) \\ \text { Type III } & \ldots & \ldots & 91 & (10.3 \%) \\ \text { Type IV } & \ldots & \ldots & 692 & (78.7 \%)\end{array}$


Glynn considered that the features most characteristic of a group IV infection were :-

(1) The onset is generally gradual : the symptoms pass slowly and less often suddenly into those broncho-pneumonia.

(2) The temperature is generally high but not sustained, and is usually marked by daily remissions of three degrees or more.

(3) Pyrexia ends by lysis, never by crisis.

These criteria are certainly fulfilled in a large number of cases due to measles in which pneumococci preponderate. A relative leucopenia appears to be less unfavourable in pneumococcal than in other forms of pneumonia.

Summary of previous investigations.-The evidence cited thus far has indicated that :-

(1) Acute interstitial pneumonia occurs in adults with measles (MacCallum ${ }^{19}$, Hektoen $^{11}$ ).

(2) Acute interstitial pneumonia is found as a primary disease in children (McNeil, Macgregor and Alexander ${ }^{20}$ ).

(3) B. influenzæ is frequently associated with this type of disease (Liston ${ }^{17}$ )

(4) B. influenzæ may pave the way for attacks by later invading organisms (Opie and Blake and others ${ }^{24}$ )

\section{Present investigations.}

In the present investigation the results of a bacteriological study of 75 cases of pneumonia occurring during successive epidemic waves of measles, are recorded.

These cases afford a fair average sample of the type of pneumonia occurring at any one time in the London area. In every case cultures were made directly from lung punctures, since no other method can be expected to afford trustworthy evidence of the nature of the organisms invading the bronchioles and alveoli. This procedure is with suitable technique neither very painful nor dangerous, and no ill-effects were observed to follow it: on the contrary in some cases it appeared to hasten resolution (as noted by Abrahams ${ }^{1}$ during the 1918 influenza, and Stewart ${ }^{28}$ ).

In a few cases blood cultures were also made successfully, but in young children the technique of blood culture is often very difficult and in many cases I was unable to secure trustworthy results. Although many faucial swabs were also examined, it was found that no reliance could be placed on the evidence so obtained for the diagnosis of the organisms primarily responsible for the pneumonia.

With regard to the $\mathrm{B}$. influenzæ it should be stated that no attempt was made to distinguish various strains, although para-influenzal bacilli and the bacillus of Bordet could be excluded. There is no doubt that several different strains showing definite morphological differences were encountered. The medium used for the cultivation of the $B$. influenzæ was agar with 10 per cent. citrated horse-blood heated to $83^{\circ} \mathrm{C}$. after storage at room temperature for two or three weeks. The growth obtained was usually luxuriant. 


\section{Discussion of results.}

Bacteriological results.-The 75 cases investigated here were selected from about 150 cases of pneumonia which occurred at the Grove Hospital in the measles epidemics during 1927-28 and 1929 to March, 1930. 52 belong to the former epidemic and 23 to the latter.

In all but one (Case 52), an attempt was made to determine the organism primarily responsible for the pneumonia, the additional case being one of death from scarlatinal nephritis five months after measles pneumonia.

B. INHLCENZA.-Organisms of the influenza group were demonstrated in 34 out of 74 cases ( 46 per cent.). Of these 34 cases, 22 occurred in the 51 (ases from the 1927-28 outbreak, and 12 from the 23 cases of the 1929-30 cpidemic.

In 23 cases out of 74 (31 per cent.) B. influenza was obtained from the lungs in pure culture.

In 5instances B. influenzæ was associated with a hæmolytic streptococcus. These cases were all fatal, the combination apparently producing a very severe form of toxæmia with early heart failure.

PNecmococcr.-In 6 cases the pneumococcus was noted in addition to B. influenzæ, and in 21 cases (28.4 per cent.) pneumococci only, or pneumococci with non-hæmolytic streptococci were found.

In this connection it may be observed that Malloch noticed an association with B. influenzæ in the majority of cases of broncho-pneumonia from which he isolated the pneumococcus. Lyon found pneumococci more frequently than B. influenzæ in primary broncho-pneumonias, but recognized that the influenza bacillus was soon overgrown in these conditions.

It seems likely that in a number of the cases here returned as primarily pneumococcal the influenza bacillus might have been obtained had cultures been made at an earlier stage of the disease.

Streptococcr.-Streptococci were found alone in 9 cases (12 per cent.). In 6 cases hæmolytic streptococci were found, and in 3 cases streptococcus viridans only.

OTHER ORGANISMS.-Staphylococci and M. catarrhalis only were found in 7 cases, but the clinical course of the disease suggested strongly in more than one of these cases, that $B$. influenzæ might have been present at an earlier stage, or that it failed to grow in cultures from the lung.

Although these findings are sufficient to indicate the importance of the B. influenzæ in measles pneumonia, they probably under-estimate the frequency with which this group was present in these cases, on account of the indubitable tendency for these organisms to die out or be replaced by others as the disease progresses. The most acute forms of pneumonia encountered were associated with B. influenzæ, and examination of the lungs revealed fulminating interstitial inflammation with hæmorrhage (Fig. 1-4).

Clinical features.-In the more acute cases it is not difficult to distinguish the 'influenzal' type of pneumonia by clinical observation alone. The toxæmia and cyanosis are out of all proportion to the physical signs in the chest. The leucocyte count is very variable : a count below 10,000 is of serious 


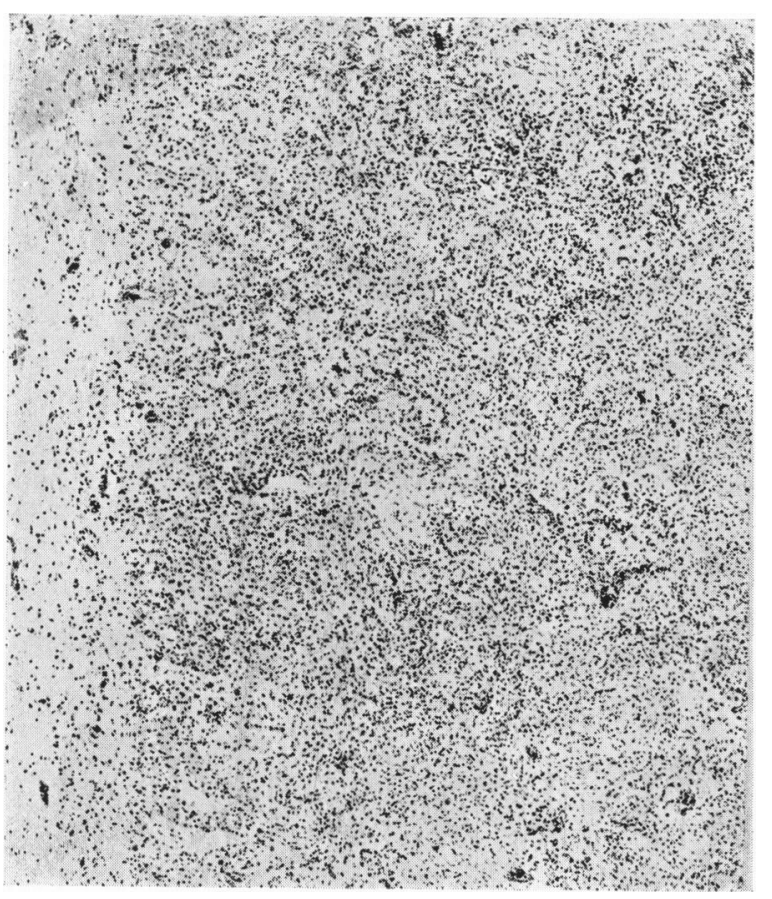

Fig. l ( 1 -in. objective).

Section of lung of male aged 1 year 7 months, showing inter stitial pneumonia of 28 days duration. The pleura is much thickened. There is no evidence of resolution. B. influenzae were obtained in pure culture.

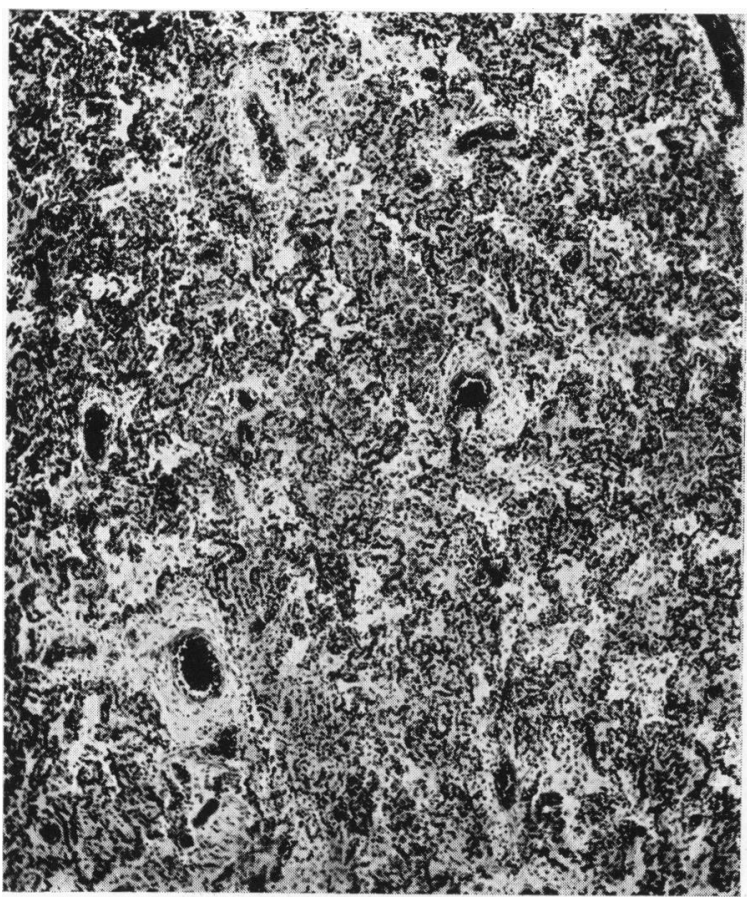

FIc. 3 (1-in. objective).

Section of lung of male aged 1 year, showing acute interstitial pneumonia of 13 days duration due to $\mathrm{B}$. influenzæ. Proliferation of fibroblasts and endothelial cells has produced so much thickening of the alveolar walls, that the alveolar space is almost obliterated,

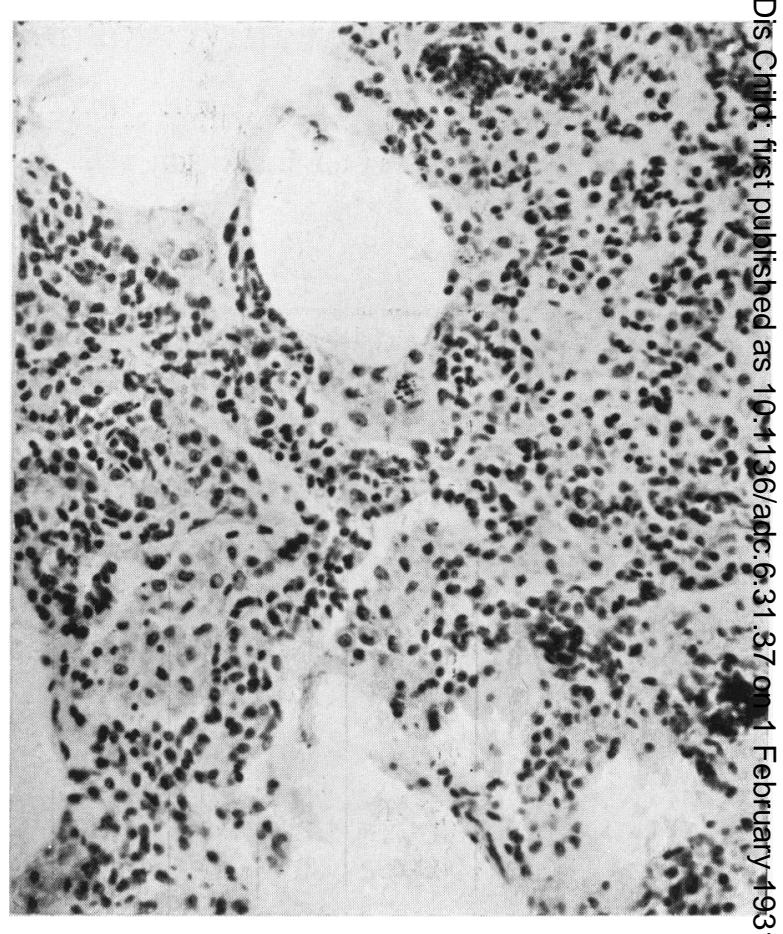

FIG. 2 (1-in. objective).

The same case as Fig. l. Section shows proliferation endothelial cells into the alveolar spaces. Macrophages ca be seen removing blood pigment. the result of hamorrhas at an earlier stage.

ญัญ

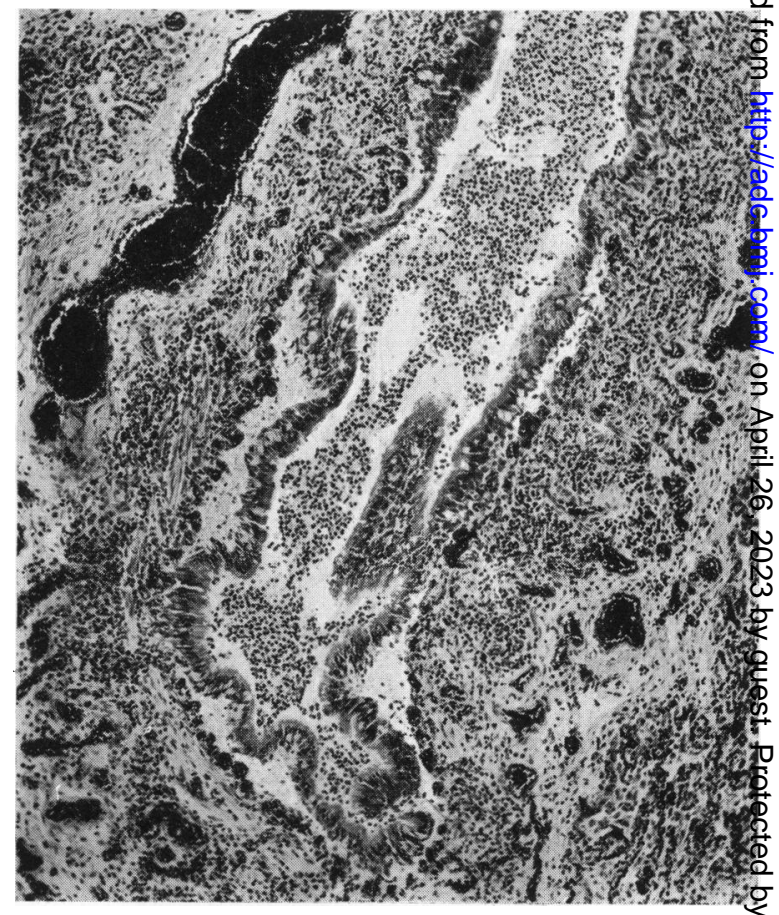

Frc. 4 ( 18 in. objective).

$\frac{0}{0}$

The same case as Fig. 3. Section through a bronchus showirc desquamation of bronchial epithelium and engorgement the peri bronchial capillaries. The inflammation is, however? not so severe as in many cases since the basement membrane appears to be intact. 
import, but unfortunately an apparently satisfactory leucocytic response is by no means an indication that the disease will pursue a favourable course (Table 3).

TABLE 3.

LEUCOCYTE COUNTS IN MEASLES PNEUMONIA.

\begin{tabular}{|c|c|c|c|c|c|c|c|c|c|c|c|}
\hline \multicolumn{3}{|c|}{$\begin{array}{l}\text { B. intluenzæ in pure } \\
\text { culture }\end{array}$} & \multicolumn{3}{|c|}{$\begin{array}{l}\text { B. influenzæe with } \\
\text { other organisms }\end{array}$} & \multicolumn{3}{|c|}{$\begin{array}{c}\text { Pneumococcus alone } \\
\text { or with } \\
\text { streptococei }\end{array}$} & \multicolumn{3}{|c|}{$\begin{array}{l}\text { Streptococei } \\
\text { hæmolytic or } \\
\text { viridans, } \\
\text { predominating }\end{array}$} \\
\hline $\begin{array}{l}\text { ('ase } \\
\text { No. }\end{array}$ & $\begin{array}{l}\text { Leuco- } \\
\text { cytes }\end{array}$ & Result & $\begin{array}{l}\text { ('xse } \\
\text { No. }\end{array}$ & $\begin{array}{l}\text { Leuco- } \\
\text { cytes }\end{array}$ & Result & $\begin{array}{l}\text { Case } \\
\text { No. }\end{array}$ & $\begin{array}{l}\text { Leuco- } \\
\text { cytes }\end{array}$ & Result & $\begin{array}{l}\text { ('ase } \\
\text { No. }\end{array}$ & $\begin{array}{l}\text { Leuco- } \\
\text { cytes }\end{array}$ & Result \\
\hline$\tilde{j}$ & 12,000 & $\mathrm{~F}$ & 25 & 12,000 & $\mathrm{~F}$ & 12 & 5,000 & $\mathrm{~F}$ & $3 \overline{1}$ & 20,000 & $\mathrm{~F}$ \\
\hline 6 & $\tilde{\delta},(000)$ & $\mathrm{F}$ & 37 & 7,000 & $\mathrm{~F}$ & 13 & 40.000 & $R$ & 41 & 35,000 & $\mathrm{~F}$ \\
\hline 8 & 8.000 & $F$ & 40 & 10,000 & $\mathrm{R}$ & 14 & 8,000 & $\mathrm{R}$ & 50 & 50,000 & R \\
\hline 38 & $8,00()$ & $\mathrm{F}$ & 43 & $15,000)$ & $\mathrm{R}$ & 1i) & 5,000 & $\mathrm{R}$ & 4 & 10,000 & $\mathrm{~F}$ \\
\hline 42 & $5,0(x)$ & $\mathrm{F}$ & 9 & 25,000 & $F$ & 19 & 43,000 & $\mathrm{R}$ & 11 & 8,000 & $\mathrm{~F}$ \\
\hline 44 & 9.0000 & $\mathrm{R}$ & 26 & 15,000 & $\mathrm{~F}$ & 33 & 9,000 & $\mathrm{R}$ & 10 & 7,000 & $\mathrm{~F}$ \\
\hline 47 & 10,000 & $\mathrm{R}$ & 27 & 20,000 & $\mathrm{~F}$ & 54 & 24,000 & $\mathrm{~F}$ & 21 & 25,000 & $R$ \\
\hline 48 & $2.5,000$ & R & 46 & 26,000 & $\mathrm{~F}$ & 55 & 14,000 & $\mathrm{~F}$ & 45 & 30,000 & $\mathrm{~F}$ \\
\hline .58 & 14.000 & $\mathrm{~F}$ & .77 & 11,000 & $\mathrm{~F}$ & 56 & 16.000 & $\mathrm{R}$ & 68 & 18,000 & $\mathrm{~F}$ \\
\hline .9) & 13,000 & $F$ & & & & & & & 71 & 18,000 & $\mathrm{~F}$ \\
\hline 63 & $* 35,000()$ & $\mathrm{R}$ & & & & & & & $7: 2$ & 20,000 & $F$ \\
\hline 66 & 13,000 & $F$ & & & & & & & & & \\
\hline 67 & $+40,000$ & $R$ & & & & & & & & & \\
\hline 74 & +45.0000 & $R$ & & & & & & & & & \\
\hline \multicolumn{3}{|c|}{$\begin{array}{c}\text { Average } 11,000 \\
\text { (uncomplicated cases) }\end{array}$} & \multicolumn{3}{|c|}{ Average 15,600} & \multicolumn{3}{|c|}{$\begin{array}{l}\text { Average }=18,200 \text { (not } \\
\text { significant owing to } \\
\text { very high standard } \\
\text { deviation of series) }\end{array}$} & \multicolumn{3}{|c|}{ Average $\quad 22.000$} \\
\hline \multicolumn{6}{|c|}{ Average of 16 recoveries $=24,000$. } & \multicolumn{6}{|c|}{ Average of 27 fatal cases } \\
\hline
\end{tabular}

* complicated by ac. strep. laryngitis.

fComplicated by mild pertussis.

The heliotrope cyanosis which is a prominent feature of these cases appears of a nature similar to that which has been so often observed in true influenza. It is not abolished by inhalation of oxygen, and Haldane ${ }^{8}$ has suggested that cyanosis of this kind may be due to alteration in the chemical constitution of the blood by a nitrite-producing organism (B. influenzæ possesses this power), the stable nitroso-hæmoglobin being produced in a manner analogous to that of the production of carboxy-hæmoglobin in carbon monoxide poisoning. In order to decide this point, it would of course be necessary to determine the dissociation curve of the blood in these cases: but there are reasons against accepting this hypothesis as an explanation of the cyanosis observed in the 'influenzal ' pneumonias of measles.*

The degree of cyanosis is very variable: it may disappear with great rapidity and reappear as suddenly. This suggests a vasomotor mechanism, with a general weakening of the capillary tone. The state of the whole

*NoTE.-Abrahams ${ }^{1}$ found that there was no loss in oxygen-carrying capacity of the blood in a series of cases of influenzal pneumonia examined by Haldane's ferricyanide method. 
peripheral circulation resembles that observed in chilblains, and it seems likely that the calcium metabolism is seriously deranged.

The whole picture is strikingly different from the ordinary cyanosis of anoxæmia, when a large area of lung is consolidated and the respirations are shallow, as in ordinary lobar pneumonia. The physical signs are often equivocal : dullness at one base with distant breath sounds may suggest the presence of fluid in nearly half the cases examined, whereas it will only be discovered in about one case in fifty (Table 1). Some consonating rales at the bases may be the only signs during life in a case which shows extensive interstitial proliferation post mortem. The pneumococcal and streptococcal cases present the signs and follow the course of the classical broncho-pneumonia of children, though in some instances the streptococcal cases appear to resemble closely the B. influenzæ pneumonias, and this resemblance is especially close when a mixture of organisms is found in the lungs. The leucocyte counts tend on an average to be higher in the catarrhal pneumonias.

It is generally possible to diagnose a pure B. influenzæ pneumonia on clinical grounds alone.

Morbid Anatomy.-Difficulty in securing post-mortem examinations has limited the amount of evidence available, but an examination of the lungs in 8 fatal cases in which B. influenzæ was predominant revealed the changes characteristic of interstitial pneumonia.

In 3 of these cases (No. 6, 37, and 42) the condition was extremely acute. In one case (No. 59) it was of longer duration ( 28 days) and revealed the early stages of organization with fibrosis.

Three cases were examined in which hæmolytic streptococci were predominant, and these revealed severe catarrhal changes with purulent bronchiolitis, and early abscess formation (Fig. 5). In one (Case 17) there was a definite abscess of the lung which was adherent to the parietal pleura.

In one case (No. 46), B. influenzæ had been replaced by a hæmolytic streptococcus with the subsequent development of empyema, but no autopsy could be obtained.

In three cases in which the pneumococcus appeared to be the primary agent, the classical broncho-pneumonic lobular consolidation was found, together with catarrhal exudate into neighbouring alveoli. The same condition was found in one case in which only staphylococcus aureus and $M$. catarrhalis were discovered.

Sequelæ.-Very few sequelæ were noted in those cases which recovered, probably because they could not be observed over long enough periods. It is unfortunate that there is no means of following up cases discharged from L.C.C. institutions, since there is little doubt that many cases of chronic pulmonary disease which later find their way into the out-patient departments of general hospitals, can be traced back to an alleged attack of measles, often many years earlier $\left(\right.$ Leys $\left.^{16}\right)$.*

*An examination of the history of $\mathbf{5 3}$ cases of non-tuberculous pulmonary fibrosis in children under 15 years of age made at Brompton Hospital in 1928 by Kitcat and Sellors ${ }^{12}$ showed that the condition was to be attributed to measles alone in 14 cases (26 per cent.), to whooping cough alone in 8 ( 15 per cent.), anil to a combination of both diseases in 16 (30 per cent.). 
Bronchiectasis.-One case (No. 50) admitted with lobar pneumonia developed pertussis while convalescent, and in the space of a few weeks presented all the signs of acute bronchiectasis with a cavity at the right base.

I have observed acute bronchiectasis in three other cases (not included in this series) in children under three years of age who developed measles during the course of pertussis. As McNeil, Macgregor, and Alexander have pointed out this event is really the result of complete destruction of the walls of the smaller bronchi; every vestige of the original wall, including cartilage, disappears, and the bronchus is represented by a space bounded directly by

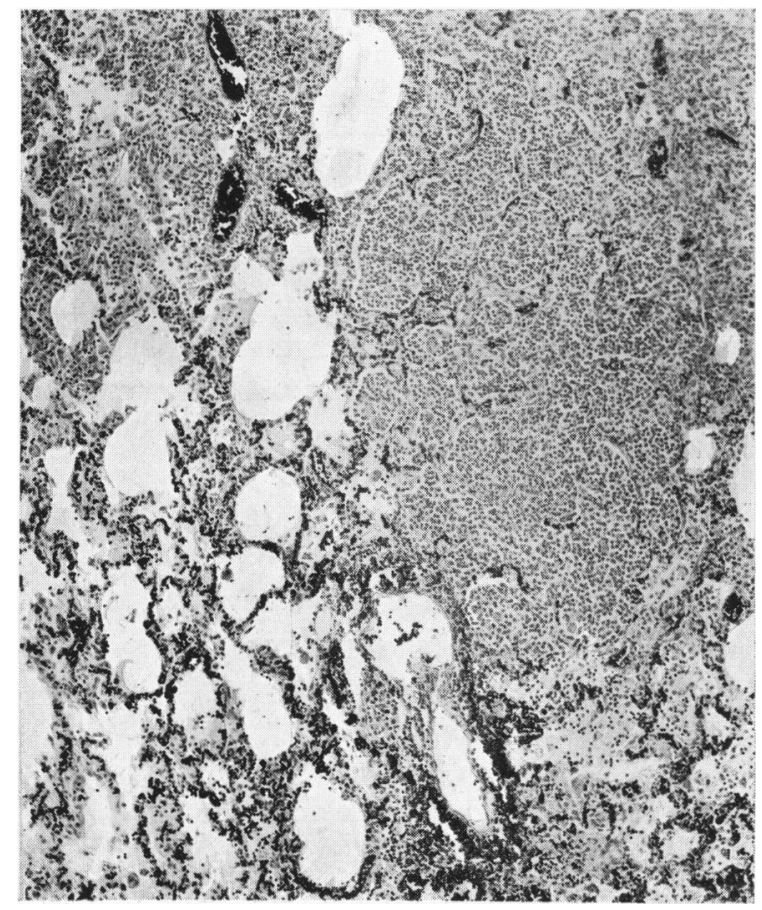

Fig. 5 ( $\left(\begin{array}{l}1 \\ 6\end{array}\right.$-in. objective $)$.

Male, aged 4 years. Broncho-pneumonia of 8 days duration due to streptorocens hemolyticus. Section shows purulent bronchitis, with peri-bronchial consolidation and early abscess formation. Surrounding the abscess there is a zone of endothelial proliferation extending into the neighbouring alveoli.

consolidated alveoli. This state of affairs is more likely to be the end result of chronic infective processes, but the combination of measles and pertussis can bring it about in a surprisingly short space of time.

In one case (No. 52), the patient was considered on clinical grounds to be suffering from fibrosis of the lung subsequent to measles pneumonia five months earlier. This patient died from acute scarlatinal nephritis and a postmortem examination of the lungs was made without revealing any notable fibrotic change. 
Prognosis.-(1) The AGE Factor.-In the 1927-28 epidemic 1,341 cases of pneumonia in measles occurred in M.A.B. (now L.C.C.) institutions with 541 deaths, these constituting 86 per cent. of the total deaths from measles during the epidemic. The case mortality, 40 per cent., is only an approximation to the truth because, in any large series, there may be a reasonable doubt in mild cases, whether broncho-pneumonia or simple bronchitis should be diagnosed, and various criteria are used in compiling statistical tables in different institutions. During this period 100 cases of pneumonia occurred at the Grove Hospital with 47 deaths. I should regard 45 per cent. with a probable error of 2.5 as a reasonable figure for the pneumonia case mortality in this epidemic.

In the present series the case mortality is not significant owing to the pre-emptive selection of fatal cases.

With regard to the prognosis in any given case, the factor of age is so well known that little remains to be said on this score, though it is perhaps worth while to mention that the low mortality among adults only holds for communities in which measles is widespread throughout the child population.

The serious outbreaks in army camps, recorded more particularly in America, are evidence of this. During the American Civil War, there occurred 67,763 cases of measles in the armies with 4,246 deaths, a case mortality of 6.27 per cent., which is closely similar to that of an ordinary epidemic among London children. In 1864 at Benton barracks, Surgeon Ira Russell had 675 cases of measles with 130 deaths, that is to say, a case mortality of just over 20 per cent. The congregation of a large number of susceptibles of a similar type, (in this case of approximately the same age), appears to lead to a rise in the fatality rate. It is probable that any adult contracting measles in London is likely to be relatively insusceptible to the disease to have escaped it for so long, but this cannot apply to immigrants from regions in which measles is not prevalent; so that it is possible that the high resistance of such people to pneumonia may be due to the fact that they can withstand the secondary invading organisms which are lethal to children, but succumb to their own when they are herded together in any large numbers.

It is worth noting that inbeciles are unusually susceptible to measles, and the mortality is high among them, owing to their low resistance to bronchopneumonia. This fact accounts for apparent irregularities in the fall of case mortality with increasing age se $\mathrm{n}$ in some statitical tables.

(2) Previous History.-A history of previous respiratory infection does not appear to be of much prognostic importance. In the present series, 52 cases had no history of any previous illness, and of these 36 died; 22 cases had a history of previous pneumonia or bronchitis, and 13 of these were fatal.

Eight cases gave a history of recent pertussis and 5 of these were fatal. There seems little doubt that measles is especially dangerous in a child which has recently suffered from pertussis. Very recent scarlet fever undoubtedly increases the risk of streptococcal empyema, and I have observed this sequence of events in three cases at the Grove Hospital.

The importance of rickets, though well known, is not easy to assess with any degree of accuracy, but the fact that the mortality from measles falls so 
heavily on those classes among whom rickets is prevalent is an indication of its significance.

From the standpoint of bacteriology the most benign cases appear to be those in which the pneumococcus alone is present. Hæmolytic streptococci, alone or associated with B. influenzæ, are far more dangerous. A pure influenzal infection probably occupies an intermediate position regarding fatality (Table 4).

TABLE 4.

BaCteriological analysis of 74 cases of measles PNeUmonia with Death Rate.

\begin{tabular}{|c|c|c|c|c|c|c|}
\hline & \multirow{2}{*}{ Bacteriological group } & \multirow{2}{*}{ Epidemic } & \multirow{2}{*}{$\begin{array}{l}\text { Total } \\
\text { cases }\end{array}$} & \multicolumn{2}{|c|}{ Death rate } & \multirow{2}{*}{ Empyema } \\
\hline & & & & Total & per cent. & \\
\hline \multirow[t]{3}{*}{ I } & \multirow[t]{3}{*}{ B. influenzæ alone. } & $1927-28$ & 13 & 10 & 76 & \\
\hline & & $1929-30$ & 10 & 7 & 70 & \\
\hline & & Total $\ldots$ & 23 & 17 & $73 \cdot 9$ & \\
\hline \multirow[t]{3}{*}{ IIA } & \multirow[t]{3}{*}{ B. influenzæ with pneumococcus. } & $1927-28$ & 4 & 1 & 25 & \\
\hline & & $1929-30$ & 1 & 1 & 100 & \\
\hline & & Total $\ldots$ & 5 & 2 & 40 & \\
\hline \multirow[t]{3}{*}{ IIB } & \multirow{3}{*}{$\begin{array}{l}\text { B. influenzæ with streptococci or } \\
\text { other micro-organisms. }\end{array}$} & $1927-28$ & 5 & 5 & 100 & 1 \\
\hline & & $1929-30$ & 1 & 1 & 100 & \\
\hline & & Total $\ldots$ & 6 & 6 & 100 & 1 \\
\hline \multirow[t]{3}{*}{ III } & \multirow{3}{*}{$\begin{array}{l}\text { Pneumococci alone or with strep- } \\
\text { tococci. }\end{array}$} & $1927-28$ & 17 & 6 & $35 \cdot 3$ & \\
\hline & & $1929-30$ & 4 & 3 & 75 & \\
\hline & & Total $\ldots$ & 21 & 9 & $42 \cdot 9$ & \\
\hline \multirow[t]{3}{*}{ IV } & \multirow[t]{3}{*}{ Streptococci alone. } & $1927-28$ & 4 & 3 & 75 & \\
\hline & & $1929-30$ & 6 & 6 & 100 & \\
\hline & & Total $\ldots$ & 10 & 9 & 90 & \\
\hline \multirow[t]{3}{*}{$\mathrm{V}$} & \multirow{3}{*}{$\begin{array}{l}\text { Staphylococcus and other micro- } \\
\text { organisms. }\end{array}$} & $1927-28$ & 7 & 5 & $71 \cdot 4$ & \\
\hline & & $1929-30$ & 0 & 0 & & \\
\hline & & Total $\ldots$ & 7 & 5 & $71 \cdot 4$ & \\
\hline \multirow[t]{3}{*}{ VI } & \multirow[t]{3}{*}{ Unclassified. } & $1927-28$ & 2 & 2 & 100 & \\
\hline & & $1929-30$ & 1 & 1 & 100 & \\
\hline & & Total $\ldots$ & 3 & 3 & 100 & \\
\hline
\end{tabular}

The leucocyte count appears to have little prognostic importance in any given case, but a very low count with $\mathrm{B}$. influenzæ present is of serious import (Table 3). 


\section{Summary and conclusions.}

(1) Micro-organisms of the influenza group were demonstrated in the lungs in 46 per cent. of a series of cases of pneumonia complicating measles occurring during successive epidemics in London. It is probable that this is an underestimate of the frequency of these organisms in measles pneumonia.

(2) Evidence is brought forward in support of the hypothesis that acute interstitial pneumonia is a frequent and important complication of measles, and that this condition is to be attributed to the agency of $\mathrm{B}$. influenzæ.

(3) Acute interstitial pneumonia can be distinguished clinically and pathologically from other forms of pneumonia, and may be regarded as an important cause of non-tuberculous chronic pulmonary disease in later life.

(4) The conclusion is reached that cases of lobar and broncho-pneumonia can be safely nursed in general measles wards without risk of dissemination, if reasonable precautions are taken against overcrowding.

(5) Hæmolytic streptococci are less important as a cause of bronchopneumonia in children than in adults with measles. The comparative rarity of empyema as a complication of measles in children is held to support this view.

\section{REFERENCES}

1. Abrahams, A., Influenza by F. G. Crookshank, Lond., 1922, 327, \& 344.

2. Bordet, J., Ann. Inst. Pasteur, Paris, 1906, XX, 731.

3. Davis, D. J., J. Am. Med. Ass., Chic., 1914, LXIV, 1814.

4. Delafield, J., Boston Med. \& Surg. J., Boston, 1884, CXI, 484.

5. Eyre, J. W. H., \& Low, C. E., Lancet, Lond., 1918, ii, 484.

6. Ferry, N. L., \& Fisher, L. W., J. Am. Med. Ass., Chic., 1926, LXXXVI, 932.

7. Glynn, E. E., \& Digby, L., Med. Res. Coun., London, 1923, Sp. Rep., 79.

8. Haldane, J. B. S., Brit. Med. J., Lond., 1929, i, 1070.

9. Hallé, M. J., Traitê de Path., Med. et de Therap. App., 1923, ii.

10. Hecht, V., Beitr. Path. Anat., Berlin, 1910, XLVIII, 263.

11. Hektoen, L., J. Am. Med. Ass., Chic., 1918, LXXI, 1201.

12. Kitcat, C. de W., \& Sellors, T., Brit. Med. J., Lond., 1928, i, 1018.

13. Knowlton, J., J. Am. Med. Ass., Chic., 1919, LXXII, 1325.

14. Levinthal, W., Ergeb. Allg. Path., Path. Anat., Berlin, 1921, XIXII, 848.

15. Lewis, D., Influenza by F. G. Crookshank, Lond., 1922.

16. Leys, D., Chronic Pulmonary Catarrh, Lond., 1927.

17. Liston, G., Arch. Dis. Childh., Lond., 1929, IV, 283.

18. Lyon, A. B., Am. J. Child. Dis., Chic., 1922, XXIII, 72.

19. MacCallum, W. G., Johns Hopkin's Hosp. Rep., Baltimore, 1921, XX. 
20. McNeil, (., Macgregor, A. R., \& Alexander, W. A., Arch. Dis. Childh., Iond., 1929, IV, $12,83,111,270$.

21. Mair, W. M. D., M.A.B. Ann. Rep., 1927-28, Lond., 1928, 262.

2.). Mallock, A., Quart. J. Med., Oxf., 1922, XV, 103.

23. Met. Asylums Bd., Ann. Rep., 1927-28, Lond., 1928, 118, 899.

24. Opie, E. L., Blake, F. G., Small, J. ('., \& Rivers, J. M. R. Epid. Resp. Iis., N.Y., 1921.

2.). Rosenow, E. ('., J. Infec. Dis., ('hic., 1920, XXVI, 469.

26. Sowden, C.. L.('.1'. Rep. on Measles Epidemic, 1927-28, 4.

27 . Steinhaus, W., Beitr. Path. Anat., Berlin, 1901, XXIX, 5204.

28. Stewart, D.. Lancet, Lond., 1930, ii, 520.

29. Med. Research ('ouncil, sigs. Bucteriology, Lond., 1930, ii, 326, 899.

30. Tunnicliffe, R., J. Am. Med. Ass., ('hic., 1926, LXXXVII, 846.

31. Winchel, A. I., \& Stillman, E. G., J. Exper. Med., N.Y., 1919, XXX, 497.

32. Wolbach, W., Bull. Johns Hopkins Hosp., Baltimore, 1919, XXX, 104.

33. Zingher, A., J. Am. Merl. Ass., Chic., 1924, LXXXIII, 432. 